\title{
江西省水库温室气体释放及其影响因素分析”
}

\author{
姜星宇 ${ }^{1,2}$, 张 路 $^{1 * *}$, 姚晓龙 ${ }^{1,2}$, 徐会显 ${ }^{1,2}$, 李 敏 ${ }^{1,2}$ \\ (1: 中国科学院南京地理与湖泊研究所湖泊与环境国家重点实验室,南京 210008) \\ (2: 中国科学院大学, 北京 100049)
}

摘 要: 对江西省柘林、白云山、陡水、洪门、仙女湖 5 个水库表面 $\mathrm{N}_{2} \mathrm{O} 、 \mathrm{CH}_{4}$ 和 $\mathrm{CO}_{2}$ 这 3 种温室气体的溶存浓度进行测定, 估算出这 3 种温室气体在水一气界面的释放速率分别为 $0.29 \sim 1.05 、 3.65 \sim 39.42$ 和 $-51.56 \sim 1383.21 \mu \mathrm{g} /\left(\mathrm{m}^{2} \cdot \mathrm{h}\right)$. 与其他 环境因素的相关性分析表明, 总氮浓度是控制 $\mathrm{N}_{2} \mathrm{O}$ 释放速率的决定性因素; $\mathrm{CH}_{4}$ 的释放速率与水体温度、透明度以及总磷 浓度的相关性显著; 而 $\mathrm{CO}_{2}$ 的释放速率与叶绿素 $\mathrm{a}$ 、总有机碳浓度等环境因素均未发现单一的相关性. 根据温室气体的全球 变暖潜能值计算得到 5 个水库温室气体总的 $\mathrm{CO}_{2}$ 等效释放速率 $\left(T F_{\text {eq- } \mathrm{CO}}\right)$ 范围为 $237.83 \sim 2267.83 \mu \mathrm{g} \mathrm{CO}_{2}-\mathrm{e} /\left(\mathrm{m}^{2} \cdot \mathrm{h}\right) . \mathrm{N}_{2} \mathrm{O}$ 、 $\mathrm{CH}_{4}$ 和 $\mathrm{CO}_{2}$ 的 $\mathrm{CO}_{2}$ 等效释放速率在 $T F_{\text {eq- } \mathrm{CO}}$ 中所占比例范围分别为 $13.94 \% \sim 83.26 \% 、 20.54 \% \sim 175.21 \%$ 和 $-140.43 \% \sim$ $60.99 \% . \mathrm{N}_{2} \mathrm{O}$ 和 $\mathrm{CH}_{4}$ 的 $\mathrm{CO}_{2}$ 等效释放速率对 $T F_{\text {eq-CO }}$ 的贡献基本相当; 在柘林和仙女湖水库中 $\mathrm{CO}_{2}$ 的贡献为负值, 而在其余 3 个水库中 $\mathrm{CO}_{2}$ 是水库所释放的最为主要的温室气体. 本实验中 5 个水库温室气体的 $T F_{\text {eq- } \mathrm{CO}}$ 相当于 $10.52 \sim 377.10 \mathrm{t} \mathrm{C} / \mathrm{a}$ 的 碳排放,占产生相同电能燃煤发电站年碳排放量的 $0.05 \% \sim 1.12 \%$.

关键词: 温室气体释放; 水库; 江西省

\section{Greenhouse gas flux at reservoirs of Jiangxi Province and its influencing factors}

\author{
JIANG Xingyu ${ }^{1,2}$, ZHANG Lu ${ }^{1 * *}$, YAO Xiaolong ${ }^{1,2}$, XU Huixian ${ }^{1,2} \&$ LI Min $^{1,2}$ \\ (1: State Key Laboratory of Lake Science and Environment, Nanjing Institute of Geography and Limnology, Chinese Academy \\ of Sciences, Nanjing 210008, P.R.China) \\ (2: University of Chinese Academy of Sciences, Beijing 100049, P.R.China)
}

\begin{abstract}
Five reservoirs located in the Jiangxi Province(Zhelin, Baiyunshan, Doushui, Hongmen and Xiannühu Reservoirs) were sampled in order to estimate the concentrations of greenhouse gas ( GHG) in the surface of these reservoirs. The calculation for diffusive fluxes of nitrous oxide $\left(\mathrm{N}_{2} \mathrm{O}\right)$, methane $\left(\mathrm{CH}_{4}\right)$ and carbon dioxide $\left(\mathrm{CO}_{2}\right)$ at the water-air interface indicated that the surface of the reservoirs was a source of $\mathrm{N}_{2} \mathrm{O}$ and $\mathrm{CH}_{4}$ during the sampling period (from 0.29 to $1.05,3.65$ to $39.42 \mu \mathrm{g} /\left(\mathrm{m}^{2} \cdot \mathrm{h}\right.$ ), respectively). Zhelin Reservoir $\left(-51.56 \mu \mathrm{g} /\left(\mathrm{m}^{2} \cdot \mathrm{h}\right)\right)$ and Xiannühu Reservoir $\left(-589.50 \mu \mathrm{g} /\left(\mathrm{m}^{2} \cdot \mathrm{h}\right)\right)$ surfaces constituted sinks for $\mathrm{CO}_{2}$. In contrast, the surface of all the other reservoirs were sources of $\mathrm{CO}_{2}\left(\right.$ from 342.53 to $\left.1383.21 \mu \mathrm{g} /\left(\mathrm{m}^{2} \cdot \mathrm{h}\right)\right)$. A significant correlation was observed between the magnitude of $\mathrm{N}_{2} \mathrm{O}$ diffusive fluxes and the TN. Water temperature, transparency and TP should affect the $\mathrm{CH}_{4}$ fluxes. There was no relationship between the $\mathrm{CO}_{2}$ emission and other environmental factors. Taking into account the global warming potential of $\mathrm{N}_{2} \mathrm{O}$ and $\mathrm{CH}_{4}$, the total fluxs of $\mathrm{CO}_{2}$ equivalents $\left(T F_{\text {eq-CO }}\right)$ was estimated that ranged from 237.83-2267.83 $\mu \mathrm{g} \mathrm{CO}_{2}-\mathrm{e} /\left(\mathrm{m}^{2} \cdot \mathrm{h}\right)$. The contribution of $\mathrm{N}_{2} \mathrm{O}, \mathrm{CH}_{4}$ and $\mathrm{CO}_{2}$ to $\mathrm{TF}_{\text {eq-CO }}$ range from $13.94 \%$ to $83.26 \%, 20.54 \%$ to $175.21 \%$ and from $-140.43 \%$ to $60.99 \%$, respectively. The contribution of $\mathrm{N}_{2} \mathrm{O}$ to $\mathrm{TF}_{\text {eq-CO}}{ }_{2}$ were similar to that of $\mathrm{CH}_{4}$ in all reservoirs. For Zhelin and Xiannühu Reservoirs, the contribution of $\mathrm{CO}_{2}$ to $\mathrm{TF}_{\mathrm{eq}-\mathrm{CO}_{2}}$ was negative, but it was the most significant in the other reservoirs. The $\mathrm{TF}_{\text {eq-CO }}$ from each reservoir were equivalent to the $10.52-377.10 \mathrm{t} \mathrm{C} / \mathrm{a}$ of the carbon emissiom that were much lower than the annual $\mathrm{CO}_{2}$ emissions from themal power plants burning coal(from $0.05 \%$ to $1.12 \%$ ).
\end{abstract}

Keywords: Greenhouse gas flux; reservoir; Jiangxi Province

* 科技部基础性工作专项 (2012FY111800-03) 资助. 2016-07-15 收稿; 2016-09-05 收修改稿. 姜星宇( 1991 ), 男,硕士研究生;E-mail: cui19910621@126.com.

** 通信作者; E-mail: luzhang@ niglas.ac.cn. 
人类活动所导致的温室气体过度排放, 被认为是引起全球变暖的主要原因 ${ }^{[1]}$. 一直以来人们认为水利 发电能够代替化石能源从本质上减少温室气体的释放, 然而最近一些研究得到的结论却并非如此 ${ }^{[2]}$. Louis 等 ${ }^{[3]}$ 的研究表明水库所释放温室气体的全球变暖潜能值相当于人类活动总释放量的 7\%, 水库是陆地生态 系统中温室气体的重要释放源 ${ }^{[4]}$. Fearnside 等 ${ }^{[5]}$ 研究发现巴西 Tucuruí Dam 水库所释放的温室气体甚至超 过了产生同样电能的化石燃料发电站. 虽然越来越多的研究表明水库是大气中温室气体的重要来源, 但也 有许多的研究认为水库所释放的温室气体量微乎其微 ${ }^{[6]}$,因此很难对该问题下一个统一的定论.

水库的修建改变了流域内碳、氮元素的生物地球化学循环. 大坝的拦蓄淹没了大量土壤、植被, 河流进 人水库后流速放缓使水体中的浮游生物碎屑以及其他颗粒态有机物沉降下来 ${ }^{[7]}$, 这些条件的改变均会影响 温室气体的产生和释放. 与河流相比水库的水力停留时间更长, 有利于污染物的累积. 就全球范围而言, 水 库的修建使河水的平均滞留时间由原来的 $16 \mathrm{~d}$ 增加到 $47 \mathrm{~d}^{[8]}$. 与湖泊相比, 水库更易受到人库河流的影响, 具有较大的补给系数, 岸线不稳, 两岸地貌易受侵蚀, 流域对水库的影响更为显著. 这些特点使得水库温室 气体的产生机制和释放速率与其他自然水体相比存在较大差别, 需要引起学者的特别关注. 水库温室气体 的产生主要来自于水库内有机物的降解 ${ }^{\left[{ }^{3}\right]}$. 影响温室气体释放速率的因素包括有机质浓度、水体初级生产 力、水体温度、 $\mathrm{pH}$ 值等 ${ }^{[2-3,9]}$.

改革开放以来我国水库大坝的建设有了突飞猛进的发展, 1951- 1977 年间世界其他国家平均每年建坝 335 座, 而中国为 420 座, 至 2005 年底中国共有大坝 22000 座, 占世界大坝总数的 $44 \%^{[8]}$. 这些大坝的修建 造成了河流流速减缓、沉降加剧, 有利于水库中有机物和营养盐积累, 导致温室气体的累积和释放. 有研究 表明随着水库库龄的增加, 水库温室气体的排放也会随之加剧 ${ }^{[9]}$, 但一直以来有关我国南方丘陵地区水库 温室气体释放的研究仍相对缺乏. 江西省是我国的水资源大省, 同时也是水库大省, 全省共有水库 10819 座, 其中大型水库 30 座, 中型水库 263 座. 水库及水资源利用率达到 72\% ( http: //www.jxsl.gov.cn/), 因而对 江西省水库温室气体释放的研究显得尤为重要. 本文通过测定江西省 5 个水库表面 $\mathrm{N}_{2} \mathrm{O} 、 \mathrm{CH}_{4}$ 和 $\mathrm{CO}_{2}$ 的溶存 浓度, 估算出这 3 种温室气体在水-气界面的释放速率, 并结合其他环境因素的测定对各环境因素与温室气 体释放速率之间的关系进行分析. 通过计算 3 种温室气体的 $\mathrm{CO}_{2}$ 等效释放速率评价不同水库中 $\mathrm{N}_{2} \mathrm{O}_{、} \mathrm{CH}_{4}$ 和 $\mathrm{CO}_{2}$ 对总温室气体释放的相对贡献, 以及水力发电作为一种清洁能源对于减少温室气体排放的相对价值.

\section{1 材料与方法}

\section{1 采样点描述}

实验选择在江西省柘林、白云山、陡水、洪门、仙女湖 5 个水库中进行,其分别位于江西省 5 大水系流域 中的修水流域、抚河流域以及赣江流域(图 1). 其中位于鄱阳湖以西修水流域的柘林水库是江西省最大的 水库; 洪门水库是抗河第一个综合性水利枢纽, 是江西省 “四大水库”之一; 赣江水系是江西省最大的水系, 其流域面积占江西省水系总流域面积的 $1 / 2$, 仙女湖水库、白云山水库和陡水水库自南向北分别位于赣江水 系支流中的袁河、富田水和上犹江流域. 水库面积范围为 $7.5 \sim 308.0 \mathrm{~km}^{2}$, 其中白云山水库为中型水库, 其余 水库均为大型水库. 在水质类型上柘林水库和白云山水库为 II 类水质, 其余水库为 III类水质, 除了白云山水 库富营养化程度为贫营养外, 其他水库营养状况均为中营养. 5 个水库修建于 $1950 \mathrm{~s}-1970 \mathrm{~s}$, 为河流筑坝拦 蓄形成, 具有防洪、灌溉、发电、养殖、旅游等多种用途, 是江西省较早修建的一批大型水利工程, 对于研究江 西省水库温室气体释放具有典型性和代表性(表 1 ).

\section{2 样品的采集和实验室分析}

于 2013 年 8 月份对江西省 5 个水库进行样品采集. 每个水库选择 1 个采样点 (坝前水深最深处), 采集 表层水样 (水面下 $0.5 \mathrm{~m}$ ), 为避免昼夜变化对实验结果产生的影响, 所有水库样品采集均在上午 $7: 00-$ 11 :00 之间进行. 将采集的水样缓慢加至 $25 \mathrm{ml}$ 的血清瓶中, 充分溢流后加人 2 3 滴 50\% 的 $\mathrm{ZnCl}_{2}$ 溶液以抑 制微生物活性, 旋紧橡胶塞并密封, 低温避光保存用于水体中 $\mathrm{N}_{2} \mathrm{O} 、 \mathrm{CH}_{4}$ 和 $\mathrm{CO}_{2}$ 溶存浓度的测定. 用 $50 \mathrm{ml}$ 离心 管收集水样用于总氮 (TN) 、总磷 (TP) 和总有机碳 (TOC) 浓度的分析. 通过多参数水质测定仪 ( YSI 6600V2, 美 国) 现场测量水库表层水体温度、pH、溶解氧浓度和盐度. 


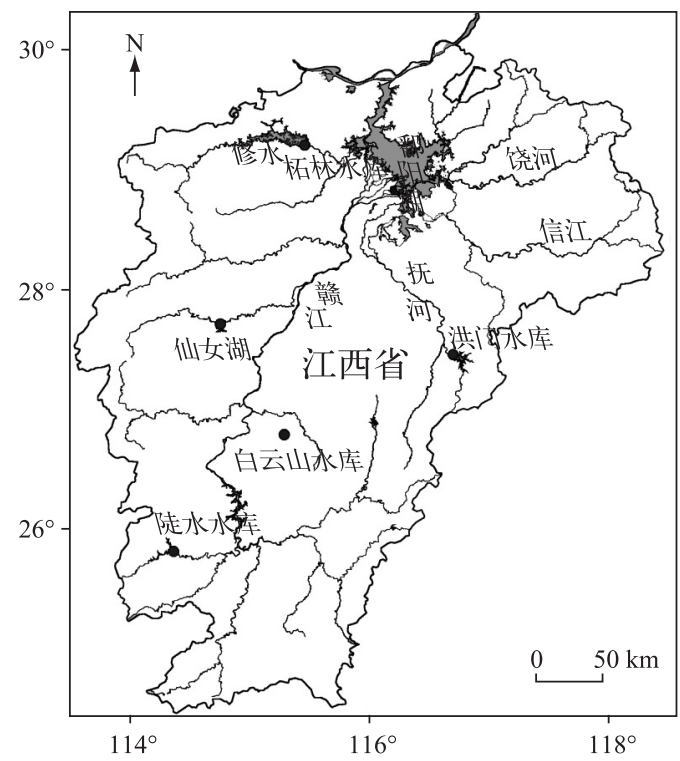

图 1 江西省水库点位分布

Fig.1 Location of the sampled reservoirs in the Jiangxi Province

表 1 水库基本理化性质

Tab.1 General characteristics of reservoirs

\begin{tabular}{lccccccccccc}
\hline \multirow{2}{*}{ 水库 } & $\begin{array}{c}\text { 经度/ } \\
\circ\end{array}$ & $\begin{array}{c}\text { 纬度/ } \\
\circ\end{array}$ & $\begin{array}{c}\text { 面积 } \\
\mathrm{km}^{2}\end{array}$ & $\begin{array}{c}\text { 平均水深/ } \\
\mathrm{m}\end{array}$ & $\begin{array}{c}\text { 库容/ } \\
\left(\times 10^{8} \mathrm{~m}^{3}\right)\end{array}$ & $\begin{array}{c}\mathrm{Chl} . \mathrm{a} / \\
(\mu \mathrm{g} / \mathrm{L})\end{array}$ & $\mathrm{pH}$ & $\begin{array}{c}\text { 温度/ 透明度/ } \\
{ }^{\circ} \mathrm{C}\end{array}$ & $\begin{array}{c}\mathrm{TN} / \\
(\mathrm{mg} / \mathrm{L})\end{array}$ & $\begin{array}{c}\mathrm{TP} / \\
(\mathrm{mg} / \mathrm{L})\end{array}$ \\
\hline 柘林 & $115.4896 \mathrm{E}$ & $29.2161 \mathrm{~N}$ & 308.0 & 16.3 & 50.17 & 3.9 & 7.9 & 31.0 & 3.5 & 0.55 & 0.008 \\
白云山 & $115.3217 \mathrm{E}$ & $26.8064 \mathrm{~N}$ & 7.5 & 12.0 & 0.94 & 8.2 & 8.5 & 32.4 & 2.0 & 0.34 & 0.036 \\
陡水 & $114.4016 \mathrm{E}$ & $25.8341 \mathrm{~N}$ & 31.0 & 28.5 & 8.22 & 5.7 & 6.4 & 30.3 & 2.3 & 0.48 & 0.013 \\
洪门 & $116.7256 \mathrm{E}$ & $27.4746 \mathrm{~N}$ & 69.6 & 17.5 & 12.16 & 4.7 & 8.5 & 32.7 & 1.3 & 1.60 & 0.038 \\
仙女湖 & $114.7908 \mathrm{E}$ & $27.7288 \mathrm{~N}$ & 56.7 & 24.5 & 3.46 & 20.6 & 8.7 & 34.8 & 1.2 & 0.79 & 0.051 \\
\hline
\end{tabular}

水库表面温室气体的溶存浓度采用顶空法测定. 先用注射器将 $12.5 \mathrm{ml}$ 的氦气注人血清瓶中以置换等体 积的水样, 在 $25^{\circ} \mathrm{C}$ 室温下将血清瓶振荡 $30 \mathrm{~min}$ 后静置 $30 \mathrm{~min}$, 使瓶中的温室气体在气液两相达到平衡状态. 然 后用 $1 \mathrm{ml}$ 气密注射器抽取顶空气体, 注人岛津 GC-2014C 型气相色谱仪中进行测定, 并记录温室气体的摩尔分 数值 ( ppm). 载气为高纯 $\mathrm{N}_{2}(99.999 \%)$, 进样口温度、柱温和电子捕获检测器 (ECD) 温度分别设定为 $60 、 60$ 和 $200^{\circ} \mathrm{C}$, 尾吹气为 $\mathrm{CH}_{4}-\mathrm{Ar}\left(\mathrm{CH}_{4}\right.$ 浓度为 $\left.5 \%, \mathrm{v} / \mathrm{v}\right)$. TN、TP 和 Chl.a 浓度参照《湖泊富营养化调查规范》 ${ }^{[10]}$ 中的方 法进行测定. 通过过硫酸盐氧化法同时测定水中的 TN 和 TP 浓度, Chl. a 浓度采用丙酮提取法测定, 经过处理 后的样品通过紫外-可见分光光度计 ( shimadzu UV-2550PC, Japan) 测定其吸光度. 采用总有机碳分析仪 ( shimadzu TOC-VCPN,Japan) 测定水体中的 TOC 浓度.

\section{$1.3 \mathrm{~N}_{2} \mathrm{O} 、 \mathrm{CH}_{4} 、 \mathrm{CO}_{2}$ 饱和度和水一气界面释放速率计算}

根据 Dalton 分压定律可以计算出温室气体在血清瓶顶空气体中的浓度 $(\mu \mathrm{g} / \mathrm{L})$; 利用 Weiss 等提供的溶解 度公式 ${ }^{[11]}$ 可以换算出水样中溶存的气体浓度,具体方法参照文献 $[12]$.

$\mathrm{N}_{2} \mathrm{O} 、 \mathrm{CH}_{4} 、 \mathrm{CO}_{2}$ 在水体中的饱和度 $(R)$ 和过饱和浓度 $(\Delta C)$ 的计算公式如下:

$$
\begin{gathered}
R=C_{\text {water }} / C_{\text {eq }} \times 100 \\
\Delta C=C_{\text {water }}-C_{\text {eq }}
\end{gathered}
$$

式中, $R$ 为温室气体的饱和度 $(\%) ; \Delta C$ 为气体的过饱和浓度 $(\mu \mathrm{g} / \mathrm{L})$, 即水体中 $\mathrm{N}_{2} \mathrm{O} 、 \mathrm{CH}_{4}$ 和 $\mathrm{CO}_{2}$ 的净产生量; 
$C_{\text {water }}$ 为水体中实测气体浓度 $(\mu \mathrm{g} / \mathrm{L}), C_{\mathrm{eq}}$ 为与大气达到平衡时水中温室气体的理论平衡浓度 $(\mu \mathrm{g} / \mathrm{L})$. 根据 Weiss ${ }^{[11,13]}$ 方程利用实测的温度和盐度以及全球年平均大气 $\mathrm{N}_{2} \mathrm{O} 、 \mathrm{CH}_{4}$ 和 $\mathrm{CO}_{2}$ 浓度计算得到 $C_{\text {eq }}$.

水-气界面 $\mathrm{N}_{2} \mathrm{O} 、 \mathrm{CH}_{4}$ 和 $\mathrm{CO}_{2}$ 的释放速率可由公式(3)、(4) ${ }^{[14]}$ 计算得到:

$$
\begin{gathered}
F=k \cdot \Delta C_{\text {surface }} \\
k=0.251 U^{2}(S c / 600)^{-0.5} \\
S c_{\mathrm{N}_{2} \mathrm{O}}=2141.2-152.56 T+5.8963 T^{2}-0.12411 T^{3}+0.0010655 T^{4} \\
S c_{\mathrm{CH}_{4}}=1909.4-120.78 T+4.1555 T^{2}-0.080578 T^{3}+0.00065777 T^{4} \\
S c_{\mathrm{CO}_{2}}=1923.6-125.06 T+4.3773 T^{2}-0.085681 T^{3}+0.00070284 T^{4}
\end{gathered}
$$

式中, $F$ 为水-气界面的气体通量 $\left(\mu \mathrm{g} /\left(\mathrm{m}^{2} \cdot \mathrm{h}\right)\right) ; \Delta C_{\text {surface }}$ 为水-气界面气体的浓度差 $(\mu \mathrm{g} / \mathrm{L})$, 即水库表面温室 气体的过饱和浓度; $k$ 为温室气体在水-气界面的气体转移系数 $(\mathrm{cm} / \mathrm{h})$, 其中 $U$ 表示水面上方风速 (由手持风 速仪测定 $)(\mathrm{m} / \mathrm{s}) ; S c$ 为淡水中 $\mathrm{N}_{2} \mathrm{O} 、 \mathrm{CH}_{4}$ 和 $\mathrm{CO}_{2}$ 的施密特常数, $S c_{\mathrm{N}_{2} 0} 、 S c_{\mathrm{CH}_{4}} 、 S c_{\mathrm{CO}_{2}}$ 分别由公式 $(5) 、(6) 、(7)^{[14]}$ 计 算得到. $T$ 为现场水温 $\left({ }^{\circ} \mathrm{C}\right)$.

通过 $\mathrm{N}_{2} \mathrm{O}$ 和 $\mathrm{CH}_{4}$ 的全球变暖潜能值 $(G W P)$ 将这 2 种温室气体的释放速率统一转换为 $\mathrm{CO}_{2}$ 等效释放速率. 在 100 年的时间尺度下 $\mathrm{N}_{2} \mathrm{O}$ 和 $\mathrm{CH}_{4}$ 的 GWP 分别是 $\mathrm{CO}_{2}$ 的 298 和 25 倍 ${ }^{[15]}$, 则 3 种温室气体总的 $\mathrm{CO}_{2}$ 等效释放 速率为:

$$
T F_{\text {eq-CO }}=F\left(\mathrm{~N}_{2} \mathrm{O}\right)_{\text {eq- }-\mathrm{CO}_{2}}+F\left(\mathrm{CH}_{4}\right)_{\text {eq- } \mathrm{CO}}+F\left(\mathrm{CO}_{2}\right)=298 F_{\mathrm{N}_{2} \mathrm{O}}+25 F_{\mathrm{CH}_{4}}+F_{\mathrm{CO}_{2}}
$$

式中, $F_{\mathrm{N}_{2} \mathrm{O}} 、 F_{\mathrm{CH}_{4}}$ 和 $F_{\mathrm{CO}}$ 分别表示 $\mathrm{N}_{2} \mathrm{O} 、 \mathrm{CH}_{4}$ 和 $\mathrm{CO}_{2}$ 的释放速率 $\left(\mu \mathrm{g} /\left(\mathrm{m}^{2} \cdot \mathrm{h}\right)\right) ; F\left(\mathrm{~N}_{2} \mathrm{O}\right)_{\text {eq-CO }}$ 和 $F\left(\mathrm{CH}_{4}\right)_{\text {eq }-\mathrm{CO}}$ 分别 表示 $\mathrm{N}_{2} \mathrm{O}$ 和 $\mathrm{CH}_{4}$ 的等效释放速率 $\left(\mu \mathrm{g} \mathrm{CO} \mathrm{CO}_{2} \mathrm{e} /\left(\mathrm{m}^{2} \cdot \mathrm{h}\right)\right)$; $\mathrm{TF}_{\text {eq-CO }}$ 为用 $\mathrm{CO}_{2}$ 表示的各温室气体等效释放速率之 和 $\left(\mu \mathrm{g} \mathrm{CO} \mathrm{CO}_{2}-\mathrm{e} /\left(\mathrm{m}^{2} \cdot \mathrm{h}\right)\right)$.

\section{4 数据处理}

本文使用 SPSS 20.0 和 Excel 2013 软件进行数据处理和统计分析. 采用 Spearman 相关系数进行数据相关 性分析;采用 Mann-Whitney U Test 进行均值比较检验.

\section{2 结果}

\section{1 水库表面温室气体的饱和度}

5 个水库中 $\mathrm{N}_{2} \mathrm{O}$ 饱和度的范围为 $127.33 \% \sim 188.63 \%$, 均值为 $148.65 \% \pm 21.08 \%$, 所有水库均表现为大气中 $\mathrm{N}_{2} \mathrm{O}$ 的源 (图 2). 其中仙女湖水库表面 $\mathrm{N}_{2} \mathrm{O}$ 饱和度为 $188.63 \%$, 明显高于其他水库; 白云山、柘林、洪门、陡水水 库表面 $\mathrm{N}_{2} \mathrm{O}$ 饱和度依次递增, 但相互之间的差异并不明显. 5 个水库表面 $\mathrm{CH}_{4}$ 饱和度的变化范围是 $1744.56 \%$ $22477.09 \%$, 其均值约为 $\mathrm{N}_{2} \mathrm{O}$ 饱和度的 46 倍 $(7925.22 \% \pm 7437.67 \%)$. 柘林、陡水、白云山、洪门、仙女湖水库 表面 $\mathrm{CH}_{4}$ 饱和度依次增加, 所有水库均表现为大气中 $\mathrm{CH}_{4}$ 的源. 与 $\mathrm{N}_{2} \mathrm{O}$ 饱和度相比, 仙女湖水库表面的 $\mathrm{CH}_{4}$ 饱和度与其他水库之间的差异更为明显 $(22477.09 \%)$, 高出其他水库一个数量级. $\mathrm{CO}_{2}$ 在水库表面的饱和度 与 $\mathrm{N}_{2} \mathrm{O}$ 和 $\mathrm{CH}_{4}$ 相比具有很大差异. 江西省 5 个水库表面 $\mathrm{CO}_{2}$ 饱和度的范围为 $77.87 \% \sim 120.38 \%$, 均值为 $105.11 \% \pm 15.39 \%$. 其中白云山、陡水、洪门水库 $\mathrm{CO}_{2}$ 饱和度依次递增, 均表现为大气中 $\mathrm{CO}_{2}$ 的源; 而仙女湖和 柘林水库表面 $\mathrm{CO}_{2}$ 未饱和, 表现为大气中 $\mathrm{CO}_{2}$ 的汇.

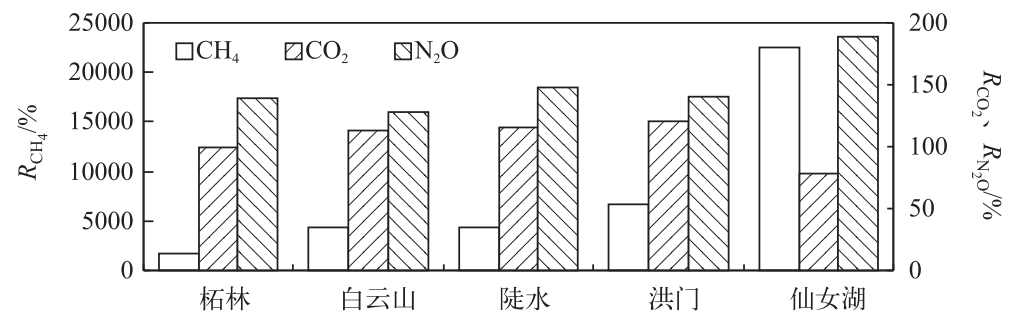

图 2 水库表面 $\mathrm{CH}_{4} 、 \mathrm{CO}_{2}$ 和 $\mathrm{N}_{2} \mathrm{O}$ 的饱和度

Fig. 2 The saturation of $\mathrm{CH}_{4}, \mathrm{CO}_{2}$ and $\mathrm{N}_{2} \mathrm{O}$ in the surface of reservoir 


\section{2 水库表面温室气体的释放速率}

江西省 5 个水库水-气界面 $\mathrm{NO}_{2}$ 释放速率的范围为 $0.29 \sim 1.05 \mu \mathrm{g} /\left(\mathrm{m}^{2} \cdot \mathrm{h}\right)$, 均值为 $0.67 \pm 0.29 \mu \mathrm{g} /\left(\mathrm{m}^{2} \cdot \mathrm{h}\right)$, 其在不同水库中的空间差异与 $\mathrm{N}_{2} \mathrm{O}$ 饱和度相比有所不同, 白云山、陡水、柘林、仙女湖、洪门水库表面 $\mathrm{NO}_{2}$ 释 放速率依次递增 (图 3). $\mathrm{CH}_{4}$ 在水一气界面释放速率的变化范围为 $3.65 \sim 29.42 \mu \mathrm{g} /\left(\mathrm{m}^{2} \cdot \mathrm{h}\right)$, 均值为 $13.30 \pm$ $10.67 \mu \mathrm{g} /\left(\mathrm{m}^{2} \cdot \mathrm{h}\right)$, 受水库表面 $\mathrm{CH}_{4}$ 饱和度的影响, 不同水库表面的 $\mathrm{CH}_{4}$ 释放速率同样表现出明显的空间差 异. 其中洪门水库和仙女湖水库的 $\mathrm{CH}_{4}$ 释放速率高出其他水库一个数量级, 而柘林、白云山、陡水水库之间的 差异并不明显. $\mathrm{CO}_{2}$ 释放速率的变化范围为 $-51.56 \sim 1383.21 \mu \mathrm{g} /\left(\mathrm{m}^{2} \cdot \mathrm{h}\right)$, 均值为 $287.66 \pm 646.85 \mu \mathrm{g} /\left(\mathrm{m}^{2} \cdot \mathrm{h}\right)$. 陡水、白云山、洪门水库 $\mathrm{CO}_{2}$ 的释放速率依次递增; 而柘林和仙女湖水库的 $\mathrm{CO}_{2}$ 释放速率为负值, 分别为 -51 . 56 和 $-589.50 \mu \mathrm{g} /\left(\mathrm{m}^{2} \cdot \mathrm{h}\right)$.

\section{3 讨论}
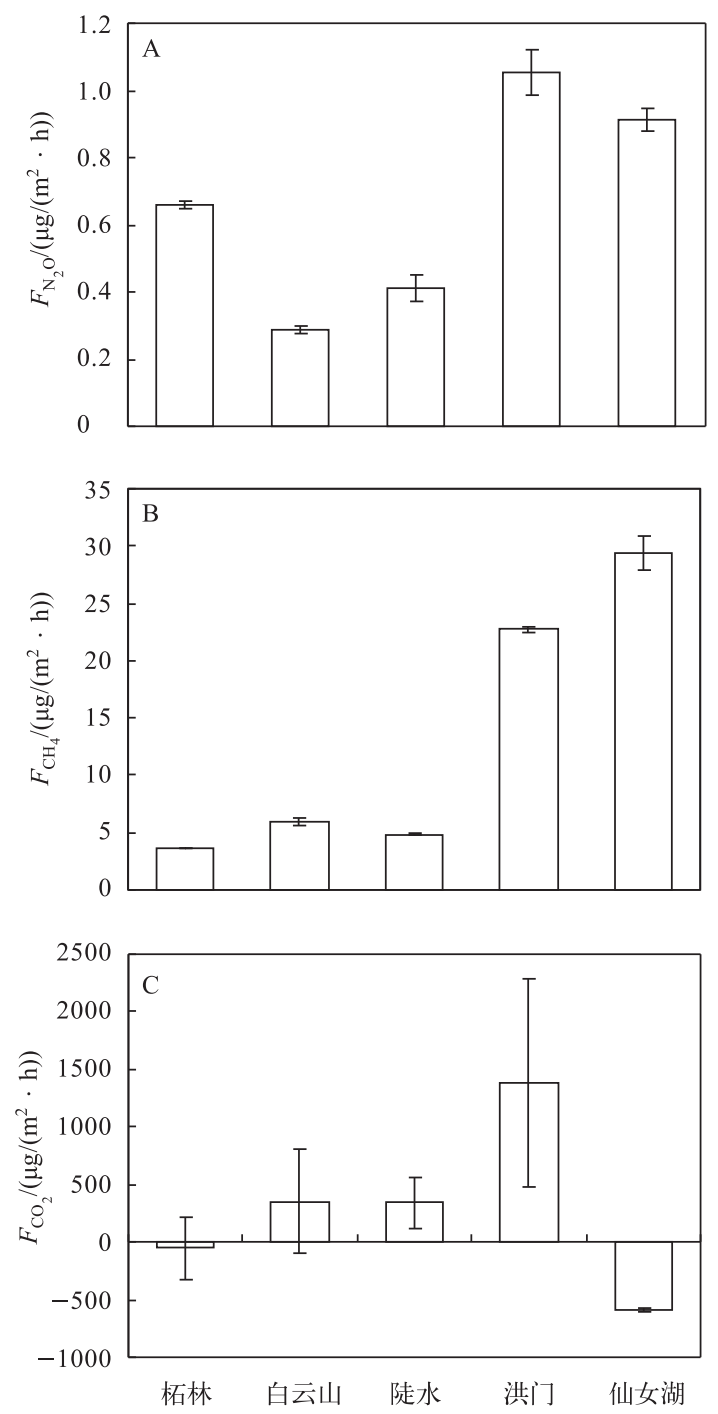

图 3 温室气体在水库表面的释放速率

Fig.3 Fluxs of greenhouse gas in the surface of reservoirs

\section{1 温室气体释放的影响因素}

$\mathrm{N}_{2} \mathrm{O}$ 在水-气界面的释放速率与水体中 $\mathrm{TN}$ 浓 度之间存在着显著的正相关关系 $(r=0.99, P<$ 0.01 ) (表 2). 水库中 $\mathrm{N}_{2} \mathrm{O}$ 的形成主要来自于水体 中硝化作用和厌氧区 (包括水库底部滞水层和沉积 物) 反硝化作用 ${ }^{[16]}$. 本研究中未能对 $\mathrm{N}_{2} \mathrm{O}$ 的具体形 成机制进行分析, 但在相关性分析中, $\mathrm{N}_{2} \mathrm{O}$ 的溶存 浓度和释放速率与硝酸盐 (反硝化作用底物) 和氨 氮 (硝化作用底物) 之间均未发现单一的相关性, 这 可能预示着 $\mathrm{N}_{2} \mathrm{O}$ 的来源并不唯一, 或者说 $\mathrm{N}_{2} \mathrm{O}$ 的 形成是硝化作用和反硝化作用多种氮循环过程共 同作用的结果, 因此, $\mathrm{N}_{2} \mathrm{O}$ 的释放速率仅与氮负荷 ( TN) 存在相关关系.

$\mathrm{CH}_{4}$ 通常在水库底部厌氧沉积物中产生, 在经 过水库好氧一厌氧界面进人好氧层后会被不断氧化 直至从水库表面释放. 通过与不同环境因素之间的 相关性分析发现, $\mathrm{CH}_{4}$ 在水一气界面的释放速率与 水库表面水温 $(P<0.05)$ 、水体透明度 $(P<0.01)$ 和 $\mathrm{TP}$ 浓度 $(P<0.01)$ 的相关性均十分显著. 许多研究 表明 $\mathrm{CH}_{4}$ 释放速率与土壤或水体温度之间存在显 著的相关性 ${ }^{[17]}$. 温度升高能够增加微生物的活性, 而与甲烷氧化菌相比产甲烷菌对温度变化的响应 更为敏感 ${ }^{[18]}$. 因此当温度在这 2 种细菌能够承受 的范围内波动时, 温度升高更能促进产甲烷菌的活 性进而有利于 $\mathrm{CH}_{4}$ 的产生和释放. 水体透明度往往 与水体中颗粒物 (有机碎屑、无机颗粒物等) 以及溶 解态有色有机物等物质浓度呈负相关关系, 因此水 体透明度较低通常预示着水库具有较高的有机物 输人量和蓄积量. 这些有机物的存在和蓄积可能会 促进 $\mathrm{CH}_{4}$ 和 $\mathrm{CO}_{2}$ 的产生和释放, 从而导致 $\mathrm{CH}_{4}$ 的释 放速率与水库透明度之间存在着显著的负相关关 系. Huttunenet 等 $^{[19]}$ 在对芬兰北部水库的研究中也 
得到了类似的结论. 除了水温和水体透明度外, $\mathrm{CH}_{4}$ 的释放速率与 $\mathrm{TP}$ 浓度之间也存在着显著的正相关关系. 水库 TP 通过影响浮游植物生物量可能间接影响了 $\mathrm{CH}_{4}$ 的释放速率. 有研究表明浮游植物光合作用固定的 有机碳会在之后的循环过程中形成 $\mathrm{CH}_{4}^{[1]}$. 浮游植物碎屑, 即湖库内源性有机质为水库底部有机物的累积提 供了丰富的易降解碳源, 同时加强了水库底部的厌氧条件, 从而为 $\mathrm{CH}_{4}$ 的产生提供了物质基础和环境条件.

表 $2 \mathrm{NO}_{2} 、 \mathrm{CH}_{4} 、 \mathrm{CO}_{2}$ 释放速率与环境因素之间的相关性分析

Tab.2 Correlation analysis between flux of $\mathrm{NO}_{2}, \mathrm{CH}_{4}, \mathrm{CO}_{2}$ and environmental factors

\begin{tabular}{lccccccrr}
\hline 温室气体 & 水温 & $\mathrm{pH}$ & 透明度 & Chl. & $\mathrm{TN}$ & $\mathrm{TP}$ & 悬浮物 & $\mathrm{TOC}$ \\
\hline $\mathrm{NO}_{2}$ & 0.60 & 0.15 & -0.50 & -0.20 & $0.99^{* *}$ & 0.50 & -0.05 & -0.30 \\
$\mathrm{CH}_{4}$ & $0.90^{*}$ & 0.87 & $-0.99^{* *}$ & 0.70 & 0.50 & $0.99^{* *}$ & 0.82 & -0.70 \\
$\mathrm{CO}_{2}$ & -0.10 & 0.00 & 0.70 & -0.90 & 0.20 & -0.70 & 0.00 & 0.30 \\
\hline
\end{tabular}

* 表明双尾检验置信水平 $<0.05$; ** 表明双尾检验置信水平 $<0.01$; 相关性分析统计样品数 $n=5$.

与 $\mathrm{CH}_{4}$ 的形成不同, $\mathrm{CO}_{2}$ 既可以在水库厌氧沉积物中产生, 也可以在好氧水体中由有机物降解生成, 但 与此同时, 浮游植物以及水体中其他大型水生植物可以通过光合作用固定 $\mathrm{CO}_{2}$. 水库中较高的初级生产力 会减弱 $\mathrm{CO}_{2}$ 在水一气界面的释放甚至使水体由 $\mathrm{CO}_{2}$ 的释放源转变为汇 ${ }^{[3]}$. 水温的变化会影响 $\mathrm{CO}_{2}$ 在水库表层 水体的溶解度 ${ }^{[20]}$, 影响水库透光层的初级生产力和有机物的降解速率 ${ }^{[21]}$, 因此水温对 $\mathrm{CO}_{2}$ 的产生和释放具 有重要影响. 作为产生 $\mathrm{CO}_{2}$ 的反应底物, 水体中的 TOC 浓度从本质上决定了 $\mathrm{CO}_{2}$ 的产生和释放. 但本研究中 并未发现 $\mathrm{CO}_{2}$ 释放速率与水温和 TOC 之间存在单一的相关关系, 水库表面 $\mathrm{CO}_{2}$ 通量受到更多环境因素的共 同影响. Yang 等 ${ }^{[22]}$ 的研究认为浮游植物在水库表面的分布决定水库是大气中 $\mathrm{CO}_{2}$ 的源还是大气中 $\mathrm{CO}_{2}$ 的 汇. 在仙女湖水库中叶绿素 a 浓度为 $20.56 \mu \mathrm{g} / \mathrm{L}$, 远高于其他 4 个水库 (均值为 $5.62 \pm 1.59 \mu \mathrm{g} / \mathrm{L}$ ), 因此可以 推测, 仙女湖水库较低的 $\mathrm{CO}_{2}$ 溶存浓度和释放速率与较强的浮游植物光合作用有关.

\section{2 不同地区水体之间温室气体释放速率的比较}

温室气体在水一气界面的释放主要包括浓度扩散和气泡释放两种形式 ${ }^{[23]}$. 因为 $\mathrm{N}_{2} \mathrm{O}$ 和 $\mathrm{CO}_{2}$ 在水体中具 有较高的溶解度, 所以它们主要以浓度扩散的形式从水库表面释放 ${ }^{[22,24]}$. 在热带水库中气泡释放是 $\mathrm{CH}_{4}$ 在 水一气界面释放的主要形式, 其次是浓度扩散; 而在温带水库中情况与之相反 ${ }^{[25]} \cdot \mathrm{CH}_{4}$ 的气泡释放是间歇性 的, 该过程通常发生在水深低于 $10 \mathrm{~m}$ 的水库中 ${ }^{[22]}$. 来自于水库底部气泡中的 $\mathrm{CH}_{4}$ 气体会在自下而上的迁移 中不断溶人水体或直接被溶解氧氧化, 因而水库深度决定了 $\mathrm{CH}_{4}$ 是否主要以气泡的形式从水库表面释放 ${ }^{[1]}$. 例如在 Petit Saut 水库水深为 $0 \sim 3 \mathrm{~m}$ 的区域, $\mathrm{CH}_{4}$ 气泡释放速率为 $164 \pm 50 \mathrm{mg} \mathrm{CH} / /\left(\mathrm{m}^{2} \cdot \mathrm{d}\right)$, 而当深度超过 $8 \mathrm{~m}$ 时 $\mathrm{CH}_{4}$ 的气泡释放速率则接近于 $0^{[24]}$. 本实验未考虑 $\mathrm{CH}_{4}$ 在水库表面的气泡释放速率, 对 $\mathrm{CH}_{4}$ 在水-气 界面总的释放速率造成了一定程度的低估, 但 5 个水库的平均水深均超过 $10 \mathrm{~m}, \mathrm{CH}_{4}$ 的气泡释放不会对其在 水库表面总的释放速率产生决定性影响.

江西典型水库中 $\mathrm{N}_{2} \mathrm{O}$ 的释放速率与世界上其他水库具有一定的可比性, 而 $\mathrm{CH}_{4}$ 和 $\mathrm{CO}_{2}$ 的释放速率则相 对较低 (表 3). 引起这 2 种温室气体释放速率相对较低的原因主要有以下两个方面: (1) 本研究计算得到的 $\mathrm{CH}_{4}$ 和 $\mathrm{CO}_{2}$ 释放速率仅代表采样时间 (白天) 内温室气体瞬时释放速率, 然而 $\mathrm{CH}_{4}$ 和 $\mathrm{CO}_{2}$ 的释放速率在昼夜 之间可能存在很大差别 ${ }^{[26]}$. 尤其是在夏季日间强烈的光照条件下, 浮游植物通过光合作用固定水体中溶存 的 $\mathrm{CO}_{2}$, 减弱了 $\mathrm{CO}_{2}$ 由水库表面向大气的释放, 甚至使部分水库成为大气中 $\mathrm{CO}_{2}$ 的汇, 而在夜间浮游植物的 呼吸作用下, $\mathrm{CO}_{2}$ 在水库表面的释放可能会表现出完全相反的结果. 由于存在昼低夜高的变化规律,仅采用 白天的采样结果往往导致计算得到的释放速率被低估. (2)江西省位于我国经济欠发达地区,地表水污染程 度较低, 且土壤类型以低有机质含量、低肥力的红壤为主 ${ }^{[27]}$, 可以推测江西省典型水库底质的有机质累积程 度较弱. 从 5 个水库的 TOC 浓度 (均值: $3.93 \pm 0.83 \mathrm{mg} / \mathrm{L}$ ) 也可以看出其水体有机质浓度处在较低水平 (表 3 ), 水体及底质中较低的有机质浓度均不利于温室气体的产生和释放. 
表 3 世界各地水库温室气体释放速率

Tab.3 The flux of greenhouse gas on the other literature

\begin{tabular}{|c|c|c|c|c|c|c|c|}
\hline \multirow{2}{*}{ 世界各地水库 } & \multirow{2}{*}{ 国家 } & \multirow{2}{*}{ 温度带 } & \multicolumn{3}{|c|}{ 释放速率/ $\left(\mu \mathrm{g} /\left(\mathrm{m}^{2} \cdot \mathrm{h}\right)\right)$} & \multirow{2}{*}{$\begin{array}{c}\text { TOC/ } \\
(\mathrm{mg} / \mathrm{L})\end{array}$} & \multirow{2}{*}{$\begin{array}{l}\text { 参考 } \\
\text { 文献 }\end{array}$} \\
\hline & & & $\mathrm{N}_{2} \mathrm{O}$ & $\mathrm{CH}_{4}$ & $\mathrm{CO}_{2}$ & & \\
\hline Jänkäläisenlampi ${ }^{1}$ & 芬兰 & 寒带 & 0.62 & 313.28 & 22000.00 & 8.90 & {$[23]$} \\
\hline Kotsamolampi ${ }^{1}$ & 芬兰 & 寒带 & -0.26 & 146.72 & 696.52 & 4.70 & {$[23]$} \\
\hline Wallula $^{1}$ & 美国 & 温带 & - & 353.28 & -17380.00 & $1.25^{\mathrm{a}}$ & {$[25]$} \\
\hline Shasta $^{1}$ & 美国 & 温带 & - & 460.00 & 56870.00 & $3.11^{\mathrm{a}}$ & {$[25]$} \\
\hline Lake Baroon $^{2}$ & 澳大利亚 & 亚热带 & $1.25 \sim 3.75$ & $95.84 \sim 312.48$ & - & $7.20^{\mathrm{b}}$ & {$[28]$} \\
\hline Little Nerang Dam² & 澳大利亚 & 亚热带 & $2.91 \sim 17.08$ & $200.00 \sim 856.48$ & - & $5.20^{\mathrm{b}}$ & {$[28]$} \\
\hline Three Gorges ${ }^{1 \mathrm{c}}$ & 中国 & 亚热带 & 22.00 & 153.33 & 190666.67 & 5.00 & {$[1]$} \\
\hline Petit Saut $^{1}$ & 圭亚那 & 热带 & 188.83 & 800.00 & 86166.52 & 5.16 & {$[24,29$} \\
\hline 柘林 ${ }^{2}$ & 中国 & 亚热带 & 0.66 & 3.65 & -51.56 & 2.49 & 本研究 \\
\hline 白云山 ${ }^{2}$ & 中国 & 亚热带 & 0.29 & 5.89 & 353.60 & 3.82 & 本研究 \\
\hline 陡水 ${ }^{2}$ & 中国 & 亚热带 & 0.41 & 4.82 & 342.53 & 4.78 & 本研究 \\
\hline 洪门 ${ }^{2}$ & 中国 & 亚热带 & 1.05 & 22.74 & 1383.21 & 3.91 & 本研究 \\
\hline 仙女湖 ${ }^{2}$ & 中国 & 亚热带 & 0.91 & 29.42 & -589.50 & 4.72 & 本研究 \\
\hline
\end{tabular}

1 : 采用静态箱法计算温室气体在水 - 气界面通量; 2 : 采用两界面扩散模型法计算温室气体在水一气界面通量. $\mathrm{a}$ : 所取数值 为水体中溶解态有机碳 (DOC) 浓度; $\mathrm{b}$ : 为水库夏季 TOC 浓度; $\mathrm{c}$ : 释放速率选取三峡坝前数据.

\section{3 温室气体的 $\mathrm{CO}_{2}$ 等效释放速率}

根据公式 $(8)$ 计算得到 5 个水库温室气体总的 $\mathrm{CO}_{2}$ 等效释放速率 (表 4). $T F_{\text {eq- } \mathrm{CO}_{2}}$ 的范围为 $237.83 \sim$ $2267.83 \mu \mathrm{g} \mathrm{CO} \mathrm{CO}_{2} \mathrm{-e} /\left(\mathrm{m}^{2} \cdot \mathrm{h}\right)$, 其中洪门水库 $T F_{\text {eq- } \mathrm{Co}}$ 远高于其他水库, 而其余 4 个水库之间的差异并不明显. 我们对水库中 $\mathrm{N}_{2} \mathrm{O} 、 \mathrm{CH}_{4}$ 和 $\mathrm{CO}_{2}$ 的 $\mathrm{CO}_{2}$ 等效释放速率在 $T F_{\text {eq- } \mathrm{CO} \mathrm{O}_{2}}$ 中所占的比重进行比较, $\mathrm{N}_{2} \mathrm{O} 、 \mathrm{CH}_{4}$ 和 $\mathrm{CO}_{2}$ 所占 比例范围分别为 $13.94 \% \sim 83.26 \% 、 20.54 \% \sim 175.21 \%$ 和 $-140.43 \% \sim 60.99 \%$. 对于世界各地大多数水库来说， $\mathrm{N}_{2} \mathrm{O}$ 在 $T F_{\text {eq-CO }}$ 中的比例通常不超过 $10 \%{ }^{[29]}$, 而江西省 5 个水库远高于这一比例, $\mathrm{N}_{2} \mathrm{O}$ 和 $\mathrm{CH}_{4}$ 对 $T F_{\text {eq- }-\mathrm{CO}_{2}}$ 的贡 献没有显著差别 $(P=0.54)$. 由于柘林水库和仙女湖水库表现为大气中 $\mathrm{CO}_{2}$ 的汇, 所以 $\mathrm{CO}_{2}$ 对 $T F_{\text {eq- }-\mathrm{CO}_{2}}$ 的贡献 为负值; 在其他 3 个水库中 $\mathrm{CO}_{2}$ 是水库所释放的最为主要的温室气体, 但其在 $T F_{\text {eq- } \mathrm{CO}_{2}}$ 中所占的比例仍低于

表 4 世界各地水库温室气体年排放量与产生相同电能燃煤电厂年排放量的比较

Tab.4 Comparison of emissions by power dams on the other literature with an equivalent thermo-power plant

\begin{tabular}{|c|c|c|c|c|c|c|c|c|c|}
\hline \multirow{2}{*}{ 水库 } & \multicolumn{3}{|c|}{$F(\mathrm{GHG})_{\mathrm{eq}-\mathrm{CO}_{2}} / T F_{\mathrm{eq}-\mathrm{CO}_{2}} / \%$} & \multirow{2}{*}{$\begin{array}{c}T F_{\text {eq-CO }} / \\
\left(\mu \mathrm{g} \mathrm{CO}_{2}-\mathrm{e} /\right. \\
\left.\left(\mathrm{m}^{2} \cdot \mathrm{h}\right)\right)\end{array}$} & \multirow{2}{*}{$\begin{array}{c}E_{\mathrm{r}}^{\mathrm{a}} / \\
(\mathrm{t} \mathrm{C/a})\end{array}$} & \multirow{2}{*}{$\begin{array}{c}\text { 年发电量/ } \\
\left(\times 10^{7} \mathrm{kWh}\right)\end{array}$} & \multirow{2}{*}{$\begin{array}{c}E_{\mathrm{p}}^{\mathrm{b}} / \\
(\mathrm{t} \mathrm{C} / \mathrm{a})\end{array}$} & \multirow{2}{*}{$\begin{array}{c}E_{\mathrm{r}} / E_{\mathrm{p}} / \\
\%\end{array}$} & \multirow{2}{*}{$\begin{array}{l}\text { 参考 } \\
\text { 文献 }\end{array}$} \\
\hline & $\mathrm{N}_{2} \mathrm{O}$ & $\mathrm{CH}_{4}$ & $\mathrm{CO}_{2}$ & & & & & & \\
\hline 柘林 & 83.26 & 38.42 & -21.68 & 237.83 & 175.01 & 63.00 & 177316.36 & 0.10 & 本研究 \\
\hline 白云山 & 14.66 & 25.09 & 60.25 & 586.92 & 10.52 & 6.73 & 18941.89 & 0.06 & 本研究 \\
\hline 陡水 & 21.09 & 20.54 & 58.38 & 586.77 & 43.46 & 29.00 & 81621.82 & 0.05 & 本研究 \\
\hline 洪门 & 13.94 & 25.06 & 60.99 & 2267.83 & 377.10 & 12.00 & 33774.55 & 1.12 & 本研究 \\
\hline 仙女湖 & 65.21 & 175.21 & -140.43 & 419.79 & 56.87 & 17.00 & 47847.27 & 0.12 & 本研究 \\
\hline 水布垭 & - & - & - & - & 24396.78 & 392.00 & 1103301.80 & 2.21 & {$[30]$} \\
\hline 三峡 & 2.57 & 10.38 & 87.05 & - & 407290.91 & $8437.00 \quad 2$ & 23746320.00 & 1.72 & {$[1]$} \\
\hline Shasta & - & - & - & - & 12577.35 & 22.96 & 64628.72 & 19.46 & {$[27]$} \\
\hline Serra de mesa & 0.10 & 0.05 & 99.86 & - & 114436.36 & 558.45 & 1571782.90 & 7.28 & {$[31]$} \\
\hline Samuel & 31.40 & 21.29 & 47.31 & - & 380454.55 & 94.61 & 266278.52 & 142.88 & {$[31]$} \\
\hline Lokka & 0.5 & 22.57 & 77.18 & - & 56807.22 & 67.50 & 189981.82 & 29.90 & {$[32]$} \\
\hline
\end{tabular}

$\mathrm{a}: E_{\mathrm{r}}=T F_{\text {eq-CO }} \times 365 \times 24 \times A / 10^{6} \times 12 / 44 ; \mathrm{b}: E_{\mathrm{p}}=$ 年发电量 $\times$ 排放因子 $/$ 产能效率 $\left(E_{\mathrm{p}}=C \times 0.09288 / 0.33\right)^{[1]}$. 
表 4 引用文献中的大部分水库. 根据水库面积 $(A)$ 计算各水库温室气体的全年释放速率,进而估算出水库 $T F_{\text {eq-CO }}$ 所对应的年碳排放量 $\left(E_{\mathrm{r}}\right)$, 用于与水电站产生相同电能的燃煤发电厂碳排放量 $\left(E_{\mathrm{p}}\right)$ 进行比较. 结果 表明, 所有水库 $E_{\mathrm{r}}$ 的范围为 $10.52 \sim 377.10 \mathrm{t} \mathrm{C} / \mathrm{a}$, 所占 $E_{\mathrm{p}}$ 的比例仅为 $0.05 \% \sim 1.12 \%$, 与产生相同电能的燃煤 发电厂碳排放量相比显得微不足道. 洪门水库与三峡水库 ${ }^{[1]}$ 和水布垭水库 ${ }^{[30]}$ 的 $E_{\mathrm{r}} / E_{\mathrm{p}}$ 处在同一数量级, 而 明显高于本实验中的其他 4 个水库, 总体来看江西省 5 个水库 $E_{\mathrm{r}} / E_{\mathrm{p}}$ 值远低于表 4 引用的大部分水库. 本实 验对温室气体的释放速率造成一定程度的低估, 且根据夏季实验数据来评估水库全年温室气体排放存在很 大的不确定性, 但仍然可以看出与火力发电相比, 以柘林、白云山、陡水、洪门、仙女湖水库为代表的江西省 水力发电能够有效的减少温室气体排放.

\section{4 结论}

1) 江西省 5 个水库中 $\mathrm{TN}$ 浓度是影响 $\mathrm{N}_{2} \mathrm{O}$ 释放速率的主要因素; $\mathrm{CH}_{4}$ 的释放速率与水温、透明度以及 $\mathrm{TP}$ 浓度的相关性显著.

2) 江西省 5 个水库中 $\mathrm{N}_{2} \mathrm{O}$ 的 $\mathrm{CO}_{2}$ 等效释放速率与 $\mathrm{CH}_{4}$ 相当, 而与其他水库相比本实验中 $\mathrm{CH}_{4}$ 和 $\mathrm{CO}_{2}$ 的 释放速率均相对较低.

3 )与火力发电相比江西省典型水库水力发电是一种十分清洁的能源.

致谢: 感谢中国科学院南京地理与湖泊研究所湖泊与环境国家重点实验室对样品分析提供的支持.

\section{5 参考文献}

[ 1 ] Zhao Y, Wu BF, Zeng Y. Spatial and temporal patterns of greenhouse gas emissions from Three Gorges Reservoir of China. Biogeosciences, 2013, 10(2) : 1219-1230. DOI: 10.5194/bg-10-1219-2013.

[ 2 ] Huang W, Bi Y, Hu Z et al. Spatio-temporal variations of GHG emissions from surface water of Xiangxi River in Three Gorges Reservoir region, China. Ecological Engineering, 2015, 83 : 28-32. DOI: 10.1016/j.ecoleng.2015.04.088.

[ 3 ] Louis VLS, Kelly CA, Duchemin É et al. Reservoir surfaces as sources of greenhouse gases to the atmosphere: A global estimate. BioScience, 2000, 50(9) : 766-775. DOI: 10.1641/0006-3568(2000)050[0766:RSASOG]2.0.CO;2.

[ 4 ] Barros N, Cole JJ, Tranvik LJ et al. Carbon emission from hydroelectric reservoirs linked to reservoir age and latitude. Nature Geoscience, 2011, 4(9) : 593-596. DOI: 10.1038/ngeo1211.

[ 5 ] Fearnside PM. Greenhouse gas emissions from a hydroelectric reservoir(Brazil’s Tucuruí Dam) and the energy policy implications. Water, Air, and Soil Pollution, 2002, 133(1/4) : 69-96. DOI: 10.1023/A:1012971715668.

[ 6 ] Dos Santos MA, Rosa LP, Sikar B et al. Gross greenhouse gas fluxes from hydro-power reservoir compared to thermo-power plants. Energy Policy, 2006, 34(4) : 481-488. DOI: 10.1016/j.enpol.2004.06.015.

[ 7 ] Rosa LP, Dos Santos MA, Matvienko B et al. Greenhouse gas emissions from hydroelectric reservoirs in tropical regions. Climatic Change, 2004, 66(1/2) : 9-21. DOI: 10.1023/B:CLIM.0000043158.52222.ee.

[ 8 ] Yang Yan. Effects of hydropower development on production and emission of $\mathrm{CH}_{4}, \mathrm{~N}_{2} \mathrm{O}$ in river[ Dissertation]. Guiyang: Guizhou University, 2009. [杨妍. 水电开发对河流 $\mathrm{CH}_{4}, \mathrm{~N}_{2} \mathrm{O}$ 产生与释放的影响分析 [学位论文]. 贵阳: 贵州大 学, 2009.]

[ 9 ] Fearnside PM. Greenhouse gas emissions from hydroelectric dams: Reply to rosa et al. Climatic Change, 2006, 75(1): 103-109. DOI: 10.1007/s10584-005-9016-z.

[10] Jin Xiangcan, Tu Qingying eds. Specification for investigation of lake eutrophication. Beijing: China Environmental Science Press, 1990: 164-178. [ 金相灿, 屠清瑛. 湖泊富营养化调查规范. 北京: 中国环境科学出版社, 1990: 164-178.]

[11] Weiss RF, Price BA. Nitrous oxide solubility in water and seawater. Marine Chemistry, 1980, 8(4):347-359. DOI: 10. 1016/0304-4203(80) 90024-9.

[12] Yao Xiaolong, Xu Huixian, Tang Chenjie et al. Denitrification potential of high suspend sediments in Poyang Lake, China. China Environmental Science, 2015,35(3):846-855. [ 姚晓龙, 徐会显, 唐陈杰等. 鄱阳湖水体悬浮物反硝化潜力模 拟研究. 中国环境科学, 2015, 35(3): 846-855.]

[13] Weiss RF. The solubility of nitrogen, oxygen and argon in water and seawater. Deep Sea Research and Oceanographic Abstracts, 1970, 17(4) : 721-735. DOI: 10.1016/0011-7471(70)90037-9. 
[14] Wanninkhof R. Relationship between wind speed and gas exchange over the ocean revisited. Limnology and Oceanography: Methods, 2014, 12(6) : 351-362. DOI: 10.4319/lom.2014.12.351.

[15] IPCC. Climate Change 2007: The physical science basis. Cambridge/New York: IPCC, 2007.

[16] Freymond CV, Wenk CB, Frame $\mathrm{CH}$ et al. Year-round $\mathrm{N}_{2} \mathrm{O}$ production by benthic $\mathrm{NO}_{\mathrm{x}}$ reduction in a monomictic southalpine lake. Biogeosciences, 2013, 10(12) : 8373-8383. DOI: 10.5194/bg-10-8373-2013.

[17] Xing Y, Xie P, Yang H et al. Methane and carbon dioxide fluxes from a shallow hypereutrophic subtropical Lake in China. Atmospheric Environment, 2005, 39(30) : 5532-5540. DOI: 10.1016/j. atmosenv.2005.06.010.

[18] Topp E, Pattey E. Soils as sources and sinks for atmospheric methane. Canadian Journal of Soil Science, 1997, 77(2) : 167-177. DOI: 10.4141/S96-107.

[19] Huttunen JT, Alm J, Liikanen A et al. Fluxes of methane, carbon dioxide and nitrous oxide in boreal lakes and potential anthropogenic effects on the aquatic greenhouse gas emissions. Chemosphere, 2003, 52 (3) : 609-621. DOI: 10.1016/ S0045-6535 ( 03 ) 00243-1.

[20] Zhao Xiaojie, Zhao Tongqian, Zheng Hua et al. Greenhouse gas emission from reservoir and its influence factors. Environmental Science, 2008, 29(8) : 2377-2384. [ 赵小杰, 赵同谦, 郑华等. 水库温室气体排放及其影响因素. 环境科学, 2008, 29(8) : 2377-2384.]

[21] Lü Yingchun, Liu Congqiang, Wang Shilu et al. Seasonal variability of $\mathrm{p}\left(\mathrm{CO}_{2}\right)$ in the two Karst reservoirs, Hongfeng and Baihua Lakes in Guizhou Province, China. Environmental Science, 2007, 28(12): 2674-2681. [吕迎春, 刘丛强, 王仕 禄等. 贵州喀斯特水库红枫湖、百花湖 $\mathrm{P}\left(\mathrm{CO}_{2}\right)$ 季节变化研究. 环境科学, 2007, 28(12): 2674-2681.]

[22] Yang L, Lu F, Zhou X et al. Progress in the studies on the greenhouse gas emissions from reservoirs. Acta Ecologica Sini$c a, 2014,34(4)$ : 204-212. DOI: 10.1016/j.chnaes.2013.05.011.

[23] Huttunen JT, Väisänen TS, Heikkinen $\mathrm{M}$ et al. Exchange of $\mathrm{CO}_{2}, \mathrm{CH}_{4}$ and $\mathrm{N}_{2} \mathrm{O}$ between the atmosphere and two northern boreal ponds with catchments dominated by peatlands or forests. Plant and Soil, 2002, 242(1) : 137-146. DOI : 10.1023/ A : 1019606410655 .

[24] Abril G, Guérin F, Richard S et al. Carbon dioxide and methane emissions and the carbon budget of a 10-year old tropical reservoir (Petit Saut, French Guiana). Global Biogeochemical Cycles, 2005, 19(4). DOI: 10.1029/2005GB002457.

[25] Soumis N, Duchemin É, Canuel R et al. Greenhouse gas emissions from reservoirs of the western United States. Global Biogeochemical Cycles, 2004, 18(3). DOI: 10.1029/2003GB002197.

[26] Li Zhe, Yao Xiao,He Ping et al. Diel variations of air-water $\mathrm{CO}_{2}$ and $\mathrm{CH}_{4}$ diffusive fluxes in the Pengxi River, Three Gorges Reservoir. J Lake Sci,2014,26(4) : 576-584. DOI: 10.18307/2014.0412. [李哲, 姚骁, 何萍等. 三峡水库澎溪河水气界面 $\mathrm{CO}_{2} 、 \mathrm{CH}_{4}$ 扩散通量昼夜动态初探. 湖泊科学, 2014,26(4) : 576-584.]

[27] Liu Zuxiang. A preliminary study on combined application of biochar and nitrogen fertility of typical upland red soil[ Dissertation]. Nanjing: Nanjing Agricultural University, 2013. [刘祖香. 生物黑炭与氮肥配施对典型旱地红壤地力提升效 果的初步研究 [ 学位论文]. 南京: 南京农业大学, 2013.]

[28] Musenze RS, Grinham A, Werner U et al. Assessing the spatial and temporal variability of diffusive methane and nitrous oxide emissions from subtropical freshwater reservoirs. Environmental Science and Technology, 2014, 48(24): 1449914507. DOI: 10.1021/es505324h.

[29] Guérin F, Abril G, Tremblay A et al. Nitrous oxide emissions from tropical hydroelectric reservoirs. Geophysical Research Letters, 2008, 35(6). DOI : 10.1029/2007GL033057.

[30] Zhao Dengzhong, Tan Debao, Wang Zhaohui et al. Measurement and analysis of greenhouse gas fluxes from Shuibuya Reservoir in Qingjiang River Basin. Journal of Yangtze River Scientific Research Institute, 2011, 28(10) : 197-204. [ 赵登忠, 谭德宝, 汪朝辉等. 清江流域水布垭水库温室气体交换通量监测与分析研究. 长江科学院院报, 2011, 28(10): 197-204. ]

[31] Santos MAD, Rosa LP, Sikar B et al. Gross greenhouse gas fluxes from hydro-power reservoir compared to thermo-power plants. Energy Policy, 2006, 34(4) : 481-488. DOI: 10.1016/j.enpol.2004.06.015.

[32] Huttunen JT, Alm J, Liikanen A et al. Fluxes of methane, carbon dioxide and nitrous oxide in boreal lakes and potential anthropogenic effects on the aquatic greenhouse gas emissions. Chemosphere, 2003, 52(3) : 609-621. DOI: 10.1016/ S0045-6535( 03) 00243-1. 